Claudia Leite Moraes 1,2,3

\title{
Adaptação transcultural para o português do instrumento "Revised Conflict Tactics Scales (CTS2)" utilizado para identificar violência entre casais
}

\author{
Portuguese-language cross-cultural adaptation \\ of the Revised Conflict Tactics Scales (CTS2), \\ an instrument used to identify violence in couples
}

Maria Helena Hasselmann 3,4

Michael E. Reichenheim 1,4

\footnotetext{
1 Departamento de Epidemiologia, Instituto de Medicina Social, Universidade do Estado do Rio de Janeiro. Rua São Francisco Xavier 524, 7o andar, Rio de Janeiro, $R J$ 20559-900, Brasil. clmoraes@ims.uerj.br michael@ims.uerj.br 2 Faculdade de Medicina, Universidade Estácio de Sá. Rua do Riachuelo 43, Rio de Janeiro, $R J$ 20230-010, Brasil. 3 Núcleo de Pesquisa das Violências, Universidade do Estado do Rio de Janeiro. Rua São Francisco Xavier 524, 7o andar, Rio de Janeiro, $R J$ 20559-900, Brasil. clmoraes@ims.uerj.br

4 Departamento de Nutrição Social, Instituto de Nutrição, Universidade do Estado do Rio de Janeiro. Rua São Francisco Xavier 524, 10 o andar, Rio de Janeiro, $R J$ 20559-900, Brasil. hasselm@ims.uerj.br
}

\begin{abstract}
This article concerns the evaluation of cross-cultural equivalence between the Revised Conflict Tactics Scales (CTS2) originally developed in English and used to identify violence in couples and a Portuguese-language version for use in Brazil. Besides a broad literature review, evaluation of conceptual and item equivalences involved expert discussion groups focusing on the existence and pertinence of the underlying theoretical concepts and corresponding component items in the Brazilian context. Semantic equivalence involved the following steps: two translations and respective back-translations; an evaluation regarding referential and general (connotative) equivalence between the original instrument and each version; further discussions with experts in order to define the final version; and pre-testing the latter on 774 women. It was possible to establish high-quality conceptual, item, and semantic equivalence between the Portuguese-language version and the original CTS2. Acceptability of the version was excellent. Although the results were encouraging, they should be reevaluated in the light of forthcoming psychometric analysis (measurement equivalence).
\end{abstract}

Key words Domestic Violence; Spouse Abuse; Questionnaires

Resumo Este artigo enfoca a avaliação da equivalência transcultural entre o instrumento Revised Conflict Tactics Scales (CTS2), concebido em inglês e usado para identificar a violência entre casais, e uma versão em português a ser proposta para uso no Brasil. Além de uma ampla revisão bibliográfica, a avaliação da equivalência conceitual e de itens, envolveu discussões de grupos de especialistas sobre a existência e pertinência em nosso meio dos conceitos teóricos subjacentes e dos itens componentes do instrumento. A avaliação da equivalência semântica constou das seguintes etapas: duas traduções e respectivas retraduções; uma avaliação subseqüente da equivalência de significado referencial e geral (conotativo) entre as retraduções e o original; novos encontros com especialistas para a definição de uma versão-síntese e a pré-testagem desta, realizada em 774 mulheres. Constatou-se boa equivalência conceitual de itens e semântica, entre a versão final em português e o original, bem como uma excelente aceitabilidade. Apesar de encorajadores, os resultados obtidos devem ser revistos à luz de avaliações psicométricas futuras.

Palavras-chave Violência Doméstica; Maus-Tratos Conjugais; Questionários 


\section{Introdução}

Em diferentes partes do mundo, a violência na família vem assumindo um crescente papel na morbi-mortalidade de mulheres, crianças e adolescentes (Gelles, 1997; Heise, 1994; Straus \& Gelles, 1995). As possíveis repercussões biopsico-sociais do fenômeno têm fomentado um crescente interesse da comunidade científica na elaboração de propostas de ação para a prevenção e o acompanhamento de suas vítimas. Porém, se ações imediatas são prioridades indiscutíveis, o desenvolvimento de linhas de investigação nessa área também merece incentivo. Conseqüentemente, requer ênfase a necessidade de aprimorar ferramentas voltadas para a detecção e acompanhamento das vítimas e suas famílias, bem como o desenvolvimento de um instrumental de aferição para ser aplicado em pesquisa.

Em muitos contextos socioculturais, incluindo o brasileiro, o desenvolvimento de programas de investigação sobre instrumentos de aferição é bastante complexo. Além de todas as minúcias requeridas na concepção, desenvolvimento e consolidação de um novo instrumento, freqüentemente é necessário utilizar um, elaborado em outra cultura, mas que para isso, ainda requer uma adaptação local. As diferenças existentes entre as definições, crenças e comportamentos relacionados ao objeto de investigação, impõem que a utilização desses instrumentos seja precedida de uma avaliação detalhada da equivalência transcultural entre o original e sua versão.

Historicamente, a adaptação de instrumentos elaborados em um outro idioma se detinha à simples tradução do original ou, excepcionalmente, à comparação literal deste com versões retraduzidas. Mais recentemente, pesquisadores de diferentes áreas temáticas têm sugerido que a avaliação semântica deva ser apenas um dos passos necessários ao processo de adaptação transcultural (Badia \& Alonso, 1995; Bravo et al., 1991; Herdman et al., 1997; Patrick et al., 1985). Apesar do avanço das reflexões a esse respeito, ainda não existe consenso quanto a melhor estratégia de adaptação. Diferentes abordagens teóricas são responsáveis pela diversidade de propostas metodológicas encontrada na literatura (Guillemin et al., 1993; Herdman et al., 1998).

Aceitando-se que na área de violência familiar é de grande interesse comparar perfis epidemiológicos e demais achados de pesquisas realizadas em diferentes localidades e culturas, parece fundamental que programas de investigação de equivalência transcultural sejam im- plementados. No contexto brasileiro, o desenvolvimento de pesquisas nessa área se torna ainda mais urgente em função do esforço demandado para construção e avaliação da qualidade de novos instrumentos de aferição e da freqüência da utilização de instrumentos elaborados em outras línguas, tanto no âmbito clínico, como no epidemiológico.

Com base no roteiro proposto por Herdmann et al. (1998) descrito a seguir, este artigo enfoca as primeiras três etapas do processo de avaliação da equivalência transcultural entre o instrumento Revised Conflict Tatics Scales CTS2, concebido por Straus et al. (1996) em língua inglesa, e uma versão - síntese em português a ser proposta para uso no Brasil.

A CTS2 faz parte de um conjunto de instrumentos de identificação de violência na família, que vem sendo elaborado pelo Family Research Laboratory nos Estados Unidos da América há cerca de duas décadas. O primeiro desses instrumentos (CTS1), teve grande aceitação na comunidade científica tendo sido utilizado em pesquisas em mais de vinte países, envolvendo cerca de 70.000 participantes (Straus et al. 1996). A partir da experiência acumulada com sua larga utilização, foram desenvolvidos instrumentos mais específicos voltados para a detecção da violência entre determinados membros do núcleo familiar.

A CTS2 é um desses instrumentos e foi concebida especificamente para identificação da violência entre indivíduos que tenham uma relação de namoro, casamento ou afins. Como os outros, é estruturado e multidimensional. Merece menção que, como entendido amplamente na literatura em questão, o termo dimensão se refere aos espaços de conteúdo abarcados pelo instrumento no plano teórico-conceitual. O termo escala que o acompanha é utilizado para conotar a sua representação empírica.

A CTS2 contém, ao todo, 78 itens que descrevem possíveis ações do respondente e, reciprocamente, de seu companheiro. Estes formam cinco escalas que representam as respectivas dimensões. Três delas são abordadas por itens abarcando táticas de resolução de conflitos através de negociação, agressão psicológica e violência física. As outras duas informam sobre as possíveis conseqüências da violência na saúde individual do respondente e de seu companheiro(a) e a existência de coerção sexual no relacionamento do casal. Do ponto de vista de consolidação das informações coletadas, Straus et al. (1996) sugerem diferentes propostas, que vão desde simples escores que consideram a presença de violência familiar caso haja uma resposta positiva em pelo menos um dos itens 
de cada escala, até escores mais complexos, ponderados pela freqüência do evento no período de referência.

O desenvolvimento da CTS2 é relativamente recente; o histórico de sua adaptação para outros idiomas e culturas, ainda mais. Até o momento, no melhor do conhecimento dos autores, estão disponíveis apenas versões em francês e espanhol, adaptações realizadas para uso no Canadá e Espanha, respectivamente (Straus, 2000). Para que seja possível uma avaliação permanente da performance do instrumento nas diferentes situações de pesquisa, os responsáveis por seu desenvolvimento sugerem que seja solicitada, através da Internet <http://www.unh.edu/frl>, uma autorização formal para sua utilização.

O modelo de adaptação proposto por Herdman et al. (1998) utiliza uma abordagem que admite a possibilidade de interlocução, mas não assume a priori a equivalência entre constructos nas diferentes culturas. O modelo é calcado na apreciação de diferentes tipos de equivalência. Inicialmente, a adaptação deve contemplar uma apreciação da pertinência dos conceitos e dimensões apreendidos pelo instrumento original na cultura alvo da nova versão (equivalência conceitual). O modelo também prescreve que se avalie a adequação de cada item do instrumento original, em termos de sua capacidade para representar tais conceitos na população onde o instrumento pretende ser utilizado (equivalência de itens). Somente então, deve-se partir para a avaliação da equivalência semântica entre esta e o original (equivalência semântica). A adequação e pertinência de aspectos operacionais na nova cultura - forma de administração, número de opções de resposta, etc. - também devem ser observadas (equivalência operacional). Na seqüência, avalia-se a equivalência entre as propriedades psicométricas do instrumento original e de sua nova versão (equivalência de mensuração). Segundo os autores, somente após percorrer os diferentes aspectos de equivalência apontados acima, é possível declarar que está estabelecida a adaptação transcultural da nova versão.

Considerando que a violência entre casais é uma das principais formas de violência familiar em nosso meio, e diante da insuficiência de ferramentas disponíveis em português para sua detecção, parece oportuno e relevante tornar disponíveis versões em português de instrumentos oriundos de programas de investigação robustos e bem estabelecidos, como é o caso da CTS2. Para isso, torna-se fundamental que esses instrumentos sejam alvo de um pro- cesso de adaptação formal antes de serem utilizados no Brasil.

O objetivo do artigo é apresentar os resultados da avaliação da equivalência conceitual, de itens e semântica entre a CTS2 original em inglês, e uma versão em português para uso em estudos epidemiológicos interessados em identificar a ocorrência de violência entre casais ou mesmo na família como um todo.

\section{Procedimentos e métodos}

\section{Avaliação da equivalência conceitual e de itens}

Esta avaliação consistiu na discussão com um grupo de especialistas, composto por cinco profissionais que atuam na área de violência familiar. O grupo reuniu três médicos epidemiologistas, uma nutricionista epidemiologista e uma antropóloga, tendo como finalidade explorar se as diferentes dimensões abarcadas pelo instrumento original (agressão psicológica, violência física e coerção sexual) na definição e apreensão da violência familiar seriam relevantes e pertinentes em nosso meio. No processo, avaliou-se a pertinência dos itens do instrumento original para a captação de cada uma dessas dimensões da violência familiar no Brasil.

A discussão focalizou especialmente o contexto brasileiro, abarcando as seguintes questões: (1) a pertinência das táticas de negociação, agressão psicológica e agressão física para resolução de conflitos entre os membros da família; (2) a existência de outras táticas de resolução de conflitos que, por serem relevantes no Brasil, devessem, necessariamente, ser incluídas em um instrumento epidemiológico de identificação da violência familiar; (3) a adequação das três dimensões presentes no questionário original (agressão psicológica, violência física e coerção sexual) para expressar o conceito de violência familiar; (4) a necessidade de inclusão no instrumento de outras dimensões da violência familiar; (5) a capacidade dos itens que compõem as cinco escalas de representar as dimensões abarcadas pelo instrumento e (6) a pertinência da classificação dos mesmos segundo a sua gravidade.

As discussões se deram à luz de uma revisão bibliográfica que priorizou as publicações das CTSs sobre os processos envolvidos em sua construção (Straus, 1979; Straus et al., 1996, 1998). Essa etapa da pesquisa visou conhecer os conceitos e definições teóricas de violência familiar, bem como as estratégias utilizadas 
para a escolha dos itens componentes. Adicionalmente, procurou-se identificar as mesmas questões no material bibliográfico publicado pelas principais instituições nacionais envolvidas com a prevenção, diagnóstico e acompanhamento de vítimas de violência familiar (ABRAPIA, 1992; BEMFAM, 1998; Branco et al., 1996; Deslandes, 1994; Guerra, 1998; MS, 1997).

\section{Avaliação da equivalência semântica}

A avaliação de equivalência semântica envolveu cinco etapas. A inicial consistiu em duas traduções do instrumento original em inglês para o português, realizadas de forma independente. Um profissional com experiência na área de violência familiar e fluente no idioma inglês foi responsável por uma tradução (T1) e um outro de nível superior, formado em letras e com especialização em inglês pela outra (T2).

$\mathrm{Na}$ segunda etapa do processo, T1 e T2 foram, respectivamente, retraduzidas por dois tradutores juramentados (R1 e R2). As retraduções ocorreram novamente de forma independente e, desta feita, mascaradas em relação ao perfil profissional dos que atuaram na etapa 1 .

Uma subseqüente avaliação formal foi realizada por um terceiro tradutor, não só proficiente e fluente nos dois idiomas, como também ligado à área de Saúde Coletiva (etapa 3). Duas questões distintas foram apreciadas. Primeiro, avaliou-se a equivalência entre o original e cada uma das retraduções, sob a perspectiva do significado referencial dos termos/palavras constituintes (Herdman et al., 1998). Este concerne as idéias ou objetos do mundo a que uma ou várias palavras se referem. Se há o mesmo significado referencial de uma palavra no original e na respectiva tradução, presumese que existe uma correspondência literal entre elas.

O segundo aspecto apreciado, concerniu o significado geral de cada item da CTS2, contrastando-se o que foi captado na tradução para o português com o original em inglês. Esta correspondência transcende a literalidade das palavras, encampando também aspectos mais sutis, como o impacto que um termo tem no contexto cultural da população alvo. A apreciação é necessária porque a correspondência literal de um termo não implica que a mesma reação emocional ou afetiva seja evocada em diferentes culturas. É indispensável uma sintonia fina que alcance também uma correspondência de percepção e impacto no respondente.

Esta questão é particularmente relevante em relação aos instrumentos usados no âmbito da violência familiar, pois uma palavra ou assertiva usada com a intenção de agredir psicologicamente, pode ter uma grande capacidade de insulto no contexto e local de origem. Por outro lado, a versão literal do termo, usada agora em uma novo contexto sócio-cultural, pode carecer de poder afrontador e não ser tão ofensiva. Neste caso, uma substituição por outro termo permitiria resgatar plenamente a equivalência desejada.

Para cada aspecto de equivalência avaliado, foi usado um formulário específico, desenhado de forma a mascarar a origem dos itens sob escrutínio, i.e., se do original ou retradução. No formulário usado para apreciar o significado referencial, optou-se por escalas analógicas visuais - Visual Analogue Scale (Streiner \& Norman, 1995). Assim, a equivalência entre pares de assertivas pôde ser julgada de forma contínua, entre 0 a $100 \%$. No outro formulário, usado na avaliação de significado geral, utilizouse uma qualificação em quatro níveis, a saber, inalterado, pouco alterado, muito alterado ou completamente alterado. Merece menção que as situações de divergência entre as avaliações de significado referencial e geral foram, explicitamente, alvo de comentários e anotações, bastante proveitosos nas discussões desenvolvidas na etapa seguinte.

A quarta etapa da avaliação semântica foi realizada pelo mesmo grupo de especialistas que participou da avaliação da equivalência conceitual e itens, tendo como objetivo identificar e encaminhar os problemas de cada uma das etapas pregressas. A partir daí, pôde-se propor uma versão-síntese, ora incorporando itens oriundos de uma das duas versões trabalhadas, ora optando-se por certas modificações para melhor atender aos critérios expostos acima.

A quinta e última etapa de avaliação envolveu um pré-teste da versão-síntese proposta. A CTS2 fez parte do conjunto de instrumentos utilizados para a detecção de violência familiar em um estudo caso-controle sobre violência na família durante a gestação e prematuridade do recém-nascido, realizado em três maternidades públicas do Município do Rio de Janeiro, durante o ano de 2000 (Moraes, 1998). Uma equipe composta por cinco entrevistadoras especialmente treinadas, e a coordenadora do trabalho de campo (C. L. M.) entrevistou 774 mães nas primeiras 48 horas de puerpério. Durante o trabalho de campo foram realizadas reuniões da equipe com o grupo de especialistas, visando discutir a aceitabilidade da versão em português e demais observações decorrentes da aplicação do instrumento. 


\section{Resultados}

\section{Apreciação da equivalência} conceitual e de itens

As discussões do grupo de especialistas e a consulta à bibliografia temática, sugeriram que os conceitos relacionados à violência familiar utilizados para a elaboração do instrumento original são pertinentes ao nosso contexto cultural, principalmente no âmbito de populações urbanas. Concordando com o proposto por Straus et al. (1996) no contexto norte-americano, julgou-se que as definições e dimensões da violência familiar no Brasil também englobam, dentre outros aspectos, a agressão psicológica, a violência física e a coerção sexual.

Segundo os especialistas, de forma geral, os 39 itens escolhidos por Straus et al. (1996) para compor o instrumento original, representam adequadamente as dimensões da violência familiar no contexto cultural brasileiro. Algumas sugestões foram feitas e incorporadas à versãosíntese proposta. Por exemplo, na escala de agressão psicológica, sugeriu-se que o item 13 onde se lia “... chamou seu companheiro de gordo ou feio?" fosse ampliado para “... chamou o seu companheiro de gordo, feio ou outra coisa parecida?". No Brasil, os termos gordo e feio não têm a mesma conotação ofensiva que nos Estados Unidos, não sendo, portanto, capazes de representar adequadamente uma agressão psicológica grave como sugerido no instrumento original.

Outra modificação sugerida, diz respeito aos itens 16 e 21 que abordam a procura de um médico em conseqüência à violência conjugal sofrida. O grupo achou interessante que os itens fossem alterados para “... médico ou serviço de saúde" já que, em nosso meio, o termo médico, isoladamente, poderia sugerir a procura exclusiva de médico particular, não tão comum em nosso país.

\section{Avaliação da equivalência semântica}

Seguindo a tradução e retradução, foi realizada uma apreciação formal da equivalência entre os itens oriundos das retraduções (R1 e R2) e os do instrumento original. De maneira geral, evidenciou-se uma boa equivalência. Como mostra a Tabela 1, somente 4 dos 39 itens de ambas retraduções apresentaram, segundo a escala analógica visual, um grau de equivalência de significado referencial aquém de $90 \%$ vis-à-vis o original. Observou-se que o significado geral se manteve inalterado em mais de $80 \%$ das assertivas. Neste aspecto da equivalência semântica, constatou-se uma discreta primazia da segunda versão sobre a primeira.

Na quarta etapa da avaliação, identificouse que todas as discrepâncias entre os itens, relativas ao significado referencial e geral, eram atribuíveis a entraves ocorridos na etapa de retradução. Ainda que, a grosso modo, a etapa anterior tenha endossado ambas as traduções, uma avaliação minuciosa levou a se optar mais pelos itens oriundos de T1 (67\% das situações), quer em sua forma original ou com alguma modificação para a elaboração da versão-síntese. O restante dos itens foram aproveitados de T2 (20\% das vezes) ou de uma composição entre as duas traduções (13\%).

Na Tabela 2, são apresentados os itens que foram modificados durante a quarta etapa. $\mathrm{Na}$

Avaliação da equivalência semântica através da apreciação da equivalência referencial e geral entre os itens das retraduções e o instrumento CTS2 original.

\begin{tabular}{|c|c|c|c|c|c|}
\hline $\begin{array}{l}\text { Grau de equivalência } \\
\text { entre as duas assertivas, } \\
\text { segundo a escala } \\
\text { analógica visual }\end{array}$ & $\begin{array}{l}\text { ficado refere } \\
\text { T1/R1* } \\
\text { número de } \\
\text { itens (\%) }\end{array}$ & $\begin{array}{l}\text { T2/R2** } \\
\text { número de } \\
\text { itens (\%) }\end{array}$ & $\begin{array}{l}\text { Julgamento } \\
\text { do avaliador }\end{array}$ & $\begin{array}{l}\text { nificado geral } \\
\text { T1/R1* } \\
\text { número de } \\
\text { itens (\%) }\end{array}$ & $\begin{array}{l}\text { T2/R2** } \\
\text { número de } \\
\text { itens (\%) }\end{array}$ \\
\hline $90-100 \%$ & $35(89,8)$ & $35(89,8)$ & Inalterado & $33(84,7)$ & $36(92,4)$ \\
\hline $70<90 \%$ & $1(2,5)$ & $2(5,1)$ & Pouco alterado & $5(12,8)$ & $3(7,6)$ \\
\hline $50<70 \%$ & $2(5,1)$ & $2(5,1)$ & Muito alterado & $1(2,5)$ & - \\
\hline$<50 \%$ & $1(2,5)$ & - & $\begin{array}{l}\text { Completamente } \\
\text { alterado }\end{array}$ & - & - \\
\hline Total & $39(100,0)$ & $39(100,0)$ & Total & $39(100,0)$ & $39(100,0)$ \\
\hline
\end{tabular}

* T1/R1 = itens provenientes da tradução 1 e respectiva retradução; ** T2/R2 = itens provenientes da tradução 2 e respectiva retradução; CTS2 $=$ Revised Conflict Scales. 
Tabela 2

Modificações realizadas durante a quarta etapa do processo de avaliação da equivalência semântica da CTS2.

\section{Item após a tradução (versão correspondente)}

(1) "Eu mostrei ao meu parceiro que eu me importava mesmo que nós discordássemos." (T1)

(2) "Expliquei ao meu parceiro qual era a coisa de que eu discordava." (T2)

(4) "Eu joguei alguma coisa em meu parceiro que poderia ferir." (T1)

"Atirei algo em meu parceiro que poderia feri-lo." (T2)

(6) "Eu tive um deslocamento, contusão ("mancha roxa"), ou tive um pequeno corte por causa de uma briga com o meu parceiro/a." (T1)

"Sofri uma torção, contusão ou pequeno corte por causa de uma briga com meu parceiro(a)." (T2)

(7) "Eu mostrei que respeitava os sentimentos do meu parceiro/a sobre uma questão." (T1)

(8) "Obriguei meu parceiro a ter relações sem usar camisinha." (T2)

(10) "Eu usei de força assim como bater, segurar ou usar uma arma para obrigar o meu parceiro/a a fazer sexo oral ou anal." (T1)

(11) "Eu usei uma faca ou arma de fogo contra o meu parceiro/a." (T1)

(13) "Eu chamei o meu parceiro/a de gordo ou feio." (T1)

(14) "Eu esmurrei ou acertei o meu parceiro/a com alguma coisa pudesse ferir/doer." (T1)

(15) "Destrui algo que pertencia ao meu parceiro(a)." (T2)

(16) "Eu fui a um médico por causa de uma briga com meu parceiro/a." (T1)

(20) "Eu disse que estava certo de que poderíamos resolver o problema." (T1)

(21) "Eu deveria ter ido a um médico por causa de uma briga com meu parceiro/a, mas não fui." (T1)

(24) "Eu usei de força (assim como bater, segurar ou usar uma arma) para obrigar o meu parceiro/a a fazer sexo comigo." (T1)

(25) "Sair bruscamente da sala, casa ou jardim durante uma discussão." (T2)

(27) "Eu dei um tabefe/bofetão no meu parceiro/a." (T1)

(30) "Eu sugeri um acordo para resolver uma desavença." (T1)

"Eu disse que tinha certeza de que poderíamos resolver determinado problema." (V2 - 42)

(33) "Eu acusei o meu parceiro/a de ser um péssimo amante." (T1)

(36) "Eu senti dores físicas que ainda doíam no dia seguinte por causa de uma briga com o meu parceiro/a." (T1)

(38) "Eu fiz ameaças para obrigar o meu parceiro/a a fazer sexo." (T1)

(39) "Concordei com a solução para uma briga que foi sugerida por meu parceiro(a)." (T2)

\section{tem proposto após etapa quatro}

"Você mostrou que se importava com ele mesmo que vocês estivessem discordando?"

"Você explicou ao seu companheiro o que você não concordava com ele?"

"Você jogou alguma coisa no seu companheiro que poderia machucá-lo?"

"Você teve uma torção, contusão, "mancha roxa" ou pequeno corte por causa de uma briga com seu companheiro?"

"Você mostrou que respeitava os pontos de vista e os sentimentos dele?"

"Você obrigou o seu companheiro a fazer sexo sem usar camisinha?"

"Você usou de força como, por exemplo, segurar ou bater nele ou usar uma arma, para obrigar o seu companheiro a fazer sexo oral ou anal com você?"

"Você usou uma faca ou arma contra o seu companheiro?"

"Você chamou o seu companheiro de gordo/a, feio/a ou alguma coisa parecida?"

"Você deu um murro ou acertou o seu companheiro com alguma coisa que pudesse machucar?"

"Você destruiu alguma coisa que pertencia ao seu companheiro de propósito?"

"Você foi a um médico ou serviço de saúde por causa de uma briga com seu companheiro?"

"Você disse para ele que achava que vocês poderiam resolver o problema?"

"Você deveria ter ido a um médico ou algum serviço de saúde por causa de uma briga com seu companheiro, mas não foi?"

"Você usou de força como, por exemplo, segurar ou bater nele ou usar uma arma para obrigar o seu companheiro a fazer sexo com você?"

"Você virou as costas e foi embora no meio de uma discussão?"

"Você deu um tabefe ou bofetada no seu companheiro?"

"Você sugeriu que procurassem juntos uma solução para resolver as diferenças ou desavenças?"

"Você acusou o seu companheiro de ser "ruim de cama"?"

"Você sentiu dores no corpo que duraram até o dia seguinte por causa de uma briga com o seu companheiro?"

"Você fez ameaças para obrigar o seu companheiro fazer sexo com você?"

"Você concordou com a solução que foi sugerida por ele?"

$\mathrm{T} 1=$ tradução $1 ; \mathrm{T} 2=$ tradução $2 ;$ CTS2 $=$ Revised Conflict Scales 
primeira coluna encontram-se as traduções desses 22 itens, destacando-se sua origem (T1 ou T2). Na segunda coluna estão os itens já modificados e incorporados na versão final da CTS2. Esta é apresentada integralmente na Tabela 3. É importante salientar que, por uma questão eminentemente operacional ligada ao estudo de fundo, a versão proposta foi adaptada para a terceira pessoa para possibilitar sua aplicação através de entrevistas.

As modificações realizadas tiveram diferentes objetivos. A maioria pretendeu tornar a versão em português mais coloquial e aceitável para a população alvo (itens 1, 2, 4, 6, 8, 10, 14, $20,24,27,36$ e 39). As alterações envolveram a substituição de pronomes e a utilização de termos mais corriqueiros em nosso meio. Em quatro situações (itens 7, 11, 13 e 33), as modificações visaram ampliar a equivalência de significado geral dos termos. No item 33, por exemplo, a expressão "péssimo amante" sugerida pela primeira tradução foi deliberadamente substituída por "ruim de cama". Entendeu-se que "péssimo amante" poderia dar a entender à respondente uma situação restrita a relações adúlteras. A substituição generalizada do termo parceiro por companheiro também serve como exemplo. Entre as camadas populares do Rio de Janeiro, parceiro corresponderia à "camarada" quando usado no âmbito das relações interpessoais ou a "colaborador" no âmbito dos negócios, o que não era a intenção do instrumento original.

Apenas o item 15 foi alterado em decorrência de uma falta de especificidade identificada no instrumento original. À proposta inicial “... destruiu alguma coisa de seu parceiro?”, foi acrescentado o complemento "de propósito" para caracterizar melhor uma situação de agressão psicológica entre o casal. Como descrito anteriormente, os itens 16 e 21 foram ampliados para “... médico ou serviço de saúde” por uma questão de ajuste ao contexto das políticas de saúde no Brasil. As mudanças nos itens 25,30 e 39 visaram mais de um dos motivos acima.

Na quinta e última etapa da avaliação semântica (pré-teste), salvo em raras situações, observou-se que o instrumento teve plena aceitabilidade. Apenas três dentre as 774 mulheres entrevistadas se recusaram a terminar a entrevista. Porém, algumas questões merecem ser apontadas. Observou-se que a aplicação da CTS2 foi cansativa para algumas respondentes, mesmo utilizando-se um sistema de escore de respostas simplificado e diferente do original, que reduziu o tempo médio de aplicação do instrumento para 13 minutos.
Outra questão apontada no pré-teste se refere à compreensão de alguns itens das escalas de negociação e coerção sexual. Com relação à primeira, constatou-se que, apesar das adaptações introduzidas na quarta etapa da apreciação, principalmente os itens 1, 2 e 30, permaneceram pouco coloquiais e a forma de construção das sentenças, pouco corriqueiras. Em algumas entrevistas foi necessário repetir as perguntas mais de uma vez para que se obtivesse uma resposta. Na escala de coerção sexual, algumas respondentes pareciam não entender o item 8 "... obrigou a fazer sexo sem usar camisinha?" como uma forma de coerção sexual, ficando até espantadas com a pergunta. Em muitas ocasiões as respondentes apenas negavam o uso regular da camisinha, não respondendo ao que havia sido perguntado.

\section{Discussão}

Até o momento, não existe na literatura uma clara recomendação sobre os métodos apropriados para realizar adaptações transculturais no âmbito da violência familiar. Nem mesmo nos campos onde algumas diretrizes existem, há consenso sobre os procedimentos necessários para adaptar instrumentos de aferição a novos contextos, culturas ou idiomas. Estratégias que vão desde uma simples tradução do original pelos próprios pesquisadores, até processos mais minuciosos como o proposto por Herdman et al. (1998) estão em franca discussão (Perneger et al., 1999).

O modelo sugerido pelos autores, foi escolhido por ser abrangente e enfatizar a necessidade de apreciação de diferentes nuanças na adaptação transcultural. Contudo, importa destacar que esse é apenas um dentre vários roteiros disponíveis na literatura na área de qualidade de vida e saúde (Health Related Quality of Life). É fundamental, pois, que se ponha à crítica cada uma das etapas envolvidas. A explicitação pormenorizada dos passos realizados, dos dilemas surgidos ao longo do processo e a experiência acumulada durante a adaptação da CTS2, pretendem enriquecer esse debate.

Apesar da constatação de equivalência conceitual, nas várias etapas de atuação do grupo de especialistas, aventou-se a possibilidade de inclusão de outras dimensões da violência entre casais na versão a ser usada no Brasil. O cárcere privado e suas variantes mais sutis, tais como, a restrição ao contato com amigos e parentes, ao trabalho, à participação em instituições da rede social de apoio, ocuparam um bom espaço nos debates. Embora esta questão 
Tabela 3

Versão-síntese da CTS2 em português.

"Mesmo que um casal se relacione bem, tem vezes em que um discorda do outro, se chateia com o outro, quer coisas diferentes ou discutem e se agridem apenas porque estão de mau humor, cansados ou por outra razão qualquer. Os casais também têm maneiras diferentes de tentar resolver seus problemas. Esta é uma lista de coisas que podem acontecer quando existem diferenças ou desavenças entre um casal. Por favor, eu gostaria de saber se você e seu (ex)companheiro fizeram cada uma dessas coisas durante a sua gravidez. Para cada uma das coisas que eu vou dizer a seguir, eu gostaria que você me dissesse se já aconteceu desde que você soube que estava grávida".

"Diante de uma desavença ou discussão entre você e seu (ex)companheiro(a) nessa gravidez ..."

\begin{tabular}{|c|c|c|}
\hline Item & Escala* & \\
\hline $1 \mathrm{a}$ & $(\mathrm{N})$ & Você mostrou que se importava com ele mesmo que vocês estivessem discordando? \\
\hline $1 \mathrm{~b}$ & & Seu companheiro(a) mostrou que se importava com você mesmo que vocês estivessem discordando? \\
\hline $2 a$ & $(\mathrm{~N})$ & Você explicou para seu companheiro(a) o que você não concordava com ele? \\
\hline $2 b$ & & Seu companheiro(a) explicou para você o que ele não concordava com você? \\
\hline $3 a$ & $(\mathrm{Pm})$ & Você insultou ou xingou o seu companheiro(a)? \\
\hline $3 b$ & & Seu companheiro(a) fez isso com você? \\
\hline $4 a$ & $(\mathrm{Fm})$ & Você jogou alguma coisa no seu companheiro(a) que poderia machucá-lo? \\
\hline $4 b$ & & Seu companheiro(a) fez isso com você? \\
\hline $5 a$ & $(\mathrm{Fm})$ & Você torceu o braço do seu companheiro(a) ou puxou o cabelo dele? \\
\hline $5 b$ & & Seu companheiro(a) fez isso com você? \\
\hline $6 a$ & $(\mathrm{Im})$ & $\begin{array}{l}\text { Você teve uma torção, contusão, "mancha roxa" ou pequeno corte por causa de uma briga } \\
\text { com seu companheiro(a)? }\end{array}$ \\
\hline $6 b$ & & $\begin{array}{l}\text { Seu companheiro(a) teve uma torção, contusão, "mancha roxa" ou pequeno corte por causa } \\
\text { de uma briga com você? }\end{array}$ \\
\hline $7 a$ & $(\mathrm{~N})$ & Você mostrou que respeitava os pontos de vista e os sentimentos dele? \\
\hline $7 b$ & & Seu companheiro(a) mostrou que respeitava os seus pontos de vista e os seus sentimentos? \\
\hline $8 a$ & $(\mathrm{Cm})$ & Você obrigou o seu companheiro(a) a fazer sexo sem usar camisinha? \\
\hline $8 b$ & & Seu companheiro(a) fez isso com você? \\
\hline $9 a$ & $(\mathrm{Fm})$ & Você deu um empurrão no seu companheiro(a)? \\
\hline $9 b$ & & Seu companheiro(a) fez isso com você? \\
\hline $10 a$ & $(\mathrm{Cg})$ & $\begin{array}{l}\text { Você usou de força como, por exemplo, segurar ou bater nele ou usar uma arma, para obrigar } \\
\text { o seu companheiro(a) a fazer sexo oral ou anal com você? }\end{array}$ \\
\hline $10 b$ & & Seu companheiro(a) fez isso? \\
\hline $11 \mathrm{a}$ & $(\mathrm{Fg})$ & Você usou uma faca ou arma contra o seu companheiro(a)? \\
\hline $11 b$ & & Seu companheiro(a) fez isso com você? \\
\hline $12 \mathrm{a}$ & $(\lg )$ & Você desmaiou ao levar uma pancada na cabeça durante uma briga com o seu companheiro(a)? \\
\hline $12 b$ & & Seu companheiro(a) desmaiou ao levar uma pancada na cabeça durante uma briga com você? \\
\hline $13 a$ & $(\mathrm{Pg})$ & Você chamou o seu companheiro(a) de gordo/a, feio/a ou alguma coisa parecida? \\
\hline $13 b$ & & Seu companheiro(a) chamou você de gorda/o, feia/o ou alguma coisa parecida? \\
\hline $14 a$ & $(\mathrm{Fg})$ & Você deu um murro ou acertou o seu companheiro(a) com alguma coisa que pudesse machucar? \\
\hline $14 b$ & & Seu companheiro(a) fez isso com você? \\
\hline
\end{tabular}

(continua) 
Tabela 3 (continuação)

\begin{tabular}{|c|c|c|}
\hline Item & Escala* & \\
\hline $15 a$ & $(\mathrm{Pg})$ & Você destruiu alguma coisa que pertencia ao seu companheiro(a) de propósito? \\
\hline $15 b$ & & Seu companheiro(a) fez isso? \\
\hline $16 a$ & $(\lg )$ & Você foi a um médico ou serviço de saúde por causa de uma briga com seu companheiro? \\
\hline $16 \mathrm{~b}$ & & Seu companheiro(a) foi ao médico ou algum serviço de saúde por causa de uma briga com você? \\
\hline $17 a$ & $(\mathrm{Fg})$ & Você sufocou ou estrangulou seu companheiro(a)? \\
\hline $17 \mathrm{~b}$ & & Seu companheiro(a) fez isso com você? \\
\hline $18 \mathrm{a}$ & $(\mathrm{Pm})$ & Você gritou ou berrou com o seu companheiro(a)? \\
\hline $18 b$ & & Seu companheiro(a) fez isso com você? \\
\hline $19 a$ & $(\mathrm{Fg})$ & Você jogou o seu companheiro(a) contra a parede com força? \\
\hline $19 \mathrm{~b}$ & & Seu companheiro(a) fez isso com você? \\
\hline $20 a$ & $(\mathrm{~N})$ & Você disse para ele que achava que vocês poderiam resolver o problema? \\
\hline $20 b$ & & Seu companheiro(a) disse que achava que você poderiam resolver o problema? \\
\hline $21 \mathrm{a}$ & $(\lg )$ & $\begin{array}{l}\text { Você deveria ter ido a um médico ou algum serviço de saúde por causa de uma briga com seu } \\
\text { companheiro, mas não foi? }\end{array}$ \\
\hline $21 b$ & & $\begin{array}{l}\text { Seu companheiro(a) deveria ter ido a um médico ou algum serviço de saúde por causa de uma } \\
\text { briga com você, mas não foi? }\end{array}$ \\
\hline $22 a$ & $(\mathrm{Fg})$ & Você deu uma surra no seu companheiro(a)? \\
\hline $22 b$ & & Seu companheiro(a) fez isso com você? \\
\hline $23 a$ & $(\mathrm{Fm})$ & Você segurou o seu companheiro(a) com força? \\
\hline $23 b$ & & Seu companheiro(a) fez isso com você? \\
\hline $24 a$ & $(\mathrm{Cg})$ & $\begin{array}{l}\text { Você usou de força como, por exemplo, segurar ou bater nele ou usar uma arma para obrigar } \\
\text { o seu companheiro(a) a fazer sexo com você? }\end{array}$ \\
\hline $24 b$ & & Seu companheiro(a) fez isso? \\
\hline $25 a$ & $(\mathrm{Pm})$ & Você virou as costas e foi embora no meio de uma discussão? \\
\hline $25 b$ & & Seu companheiro(a) fez isso? \\
\hline $26 a$ & $(\mathrm{Cm})$ & Você insistiu em fazer sexo quando o seu companheiro(a) não queria sem usar força física? \\
\hline $26 b$ & & Seu companheiro(a) fez isso com você? \\
\hline $27 a$ & $(\mathrm{Fm})$ & Você deu um tabefe ou bofetada no seu companheiro(a)? \\
\hline $27 b$ & & Seu companheiro(a) fez isso com você? \\
\hline $28 \mathrm{a}$ & $(\lg )$ & Você quebrou um osso por causa de uma briga com o seu companheiro(a)? \\
\hline $28 b$ & & Seu companheiro(a) quebrou um osso por causa de uma briga com você? \\
\hline $29 a$ & (Cg) & Você fez ameaças para obrigar o seu companheiro(a) fazer sexo oral ou anal com você? \\
\hline $29 b$ & & Seu companheiro(a) fez isso com você? \\
\hline $30 a$ & $(\mathrm{~N})$ & Você sugeriu que procurassem juntos uma solução para resolver as diferenças ou desavenças? \\
\hline $30 b$ & & Seu companheiro(a) fez isso? \\
\hline $31 \mathrm{a}$ & $(\mathrm{Fg})$ & Você queimou ou derramou líquido quente em seu companheiro(a) de propósito? \\
\hline $31 b$ & & Seu companheiro(a) fez isso com você? \\
\hline $32 a$ & $(\mathrm{Cm})$ & Você insistiu para que seu companheiro(a) fizesse sexo oral ou anal com você sem usar força física? \\
\hline $32 b$ & & Seu companheiro(a) fez isso com você? \\
\hline
\end{tabular}

(continua) 


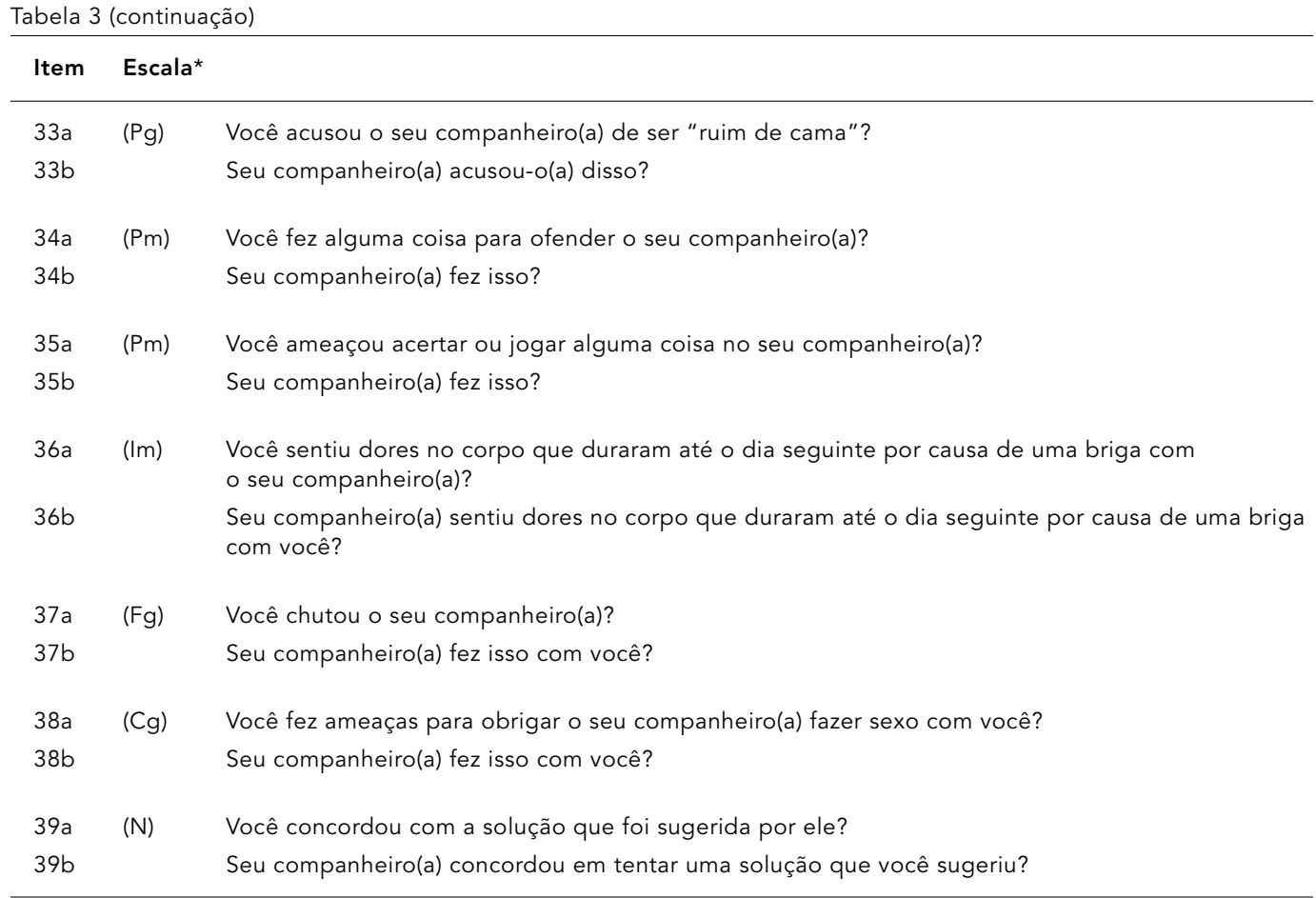

*Legenda para as escalas: $\mathrm{Cg}=$ coerção sexual grave; $\mathrm{Cm}=$ coerção sexual menor; Fg = violência física grave; $\mathrm{Fm}=$ violência física menor; lg = injúria grave; Im = injúria menor; $\mathrm{N}=$ negociação; Pg = agressão psicológica grave; $\mathrm{Pm}=$ agressão psicológica menor; CTS2 = Revised Conflict Tactics Scales.

já tenha sido trazida à baila por outros grupos de pesquisa (Heise et al., 1994; INCLEN, 2000), decidiu-se por não incluí-los no presente estudo pois julgou-se que isso requereria uma avaliação mais aprofundada. Primeiro, seria necessário responder se, de fato, o cárcere constitui uma dimensão separada das demais já contempladas na CTS2 ou se este poderia ser entendido como uma manifestação de agressão psicológica não abrangida pelo instrumento original. Nas duas hipóteses, a incorporação de novos itens sobre o cárcere necessitaria passar por uma avaliação formal, semelhante àquela demandada na construção de um novo instrumento. Em se admitindo, por outro lado, que os itens conformassem apenas um conjunto superposto ao espaço de conteúdo representado pelos outros já incluídos no instrumento original, ter-se-ia redundância, tornando a informação específica sobre o cárcere desnecessária para a identificação da respectiva dimensão.

Ainda que os especialistas tenham considerado todos os itens da CTS2 pertinentes ao contexto cultural brasileiro, aventou-se a possibilidade de inclusão de outros que contemplassem ações de violência também comuns no nosso meio. Com base em evidências (Heise et al., 1994; Soares et al., 1999) foram sugeridos alguns itens descrevendo atitudes depreciati- vas da capacidade intelectual do companheiro ou que traduzissem outras formas de opressão psicológica entre o casal, tal como o confisco de pertences ou documentos pessoais. Aqui também, julgou-se prudente modificar o mínimo possível a estrutura do instrumento, uma vez que já se tinha avaliado positivamente a equivalência de itens em termos de representação das dimensões. Ademais, não manter o conjunto original poderia promover uma alteração das propriedades psicométricas, algo indesejável quando se almeja uma adaptação transcultural satisfatória. Nada impede a inclusão de novos itens em versões futuras, desde que esta decisão seja sustentada por uma rigorosa e sistemática avaliação (Streiner \& Norman, 1995).

Já uma redução do número de itens foi aventada após a realização do pré-teste. O fato da aplicação da CTS2 ser cansativa para algumas respondentes, principalmente na ausência de situação de violência na família, talvez se explique pela sua inserção no questionário multidimensional do estudo de fundo, levando a um aumento substantivo da duração da entrevista. Mas se o uso de questionários multifacetados constitui o dia-a-dia dos estudos epidemiológicos, seria interessante recomendar uma versão mais breve a ser utilizada nestas si- 
tuações. Vale enfatizar novamente que, mesmo em se aceitando a equivalência transcultural na versão completa, seria necessário que a reduzida também fosse alvo de um escrutínio formal, principalmente no que tange à equivalência de itens e de mensuração.

Uma outra questão percebida diz respeito à necessidade de aprofundar a discussão sobre a classificação dos itens em "menores" e "graves" (detalhes na Tabela 3), problema também levantado por Bucquet et al. (1990) na avaliação da adaptação ao idioma francês do instrumento Nottingham Health Profile sobre qualidade de vida. No presente estudo, a falta de correspondência conotativa concernente aos termos gordo e feio apontada na seção de resultados, instiga a reflexão. Lançados como ofensas graves nos Estados Unidos, no Brasil, os termos não parecem ser tão chocantes assim. Possivelmente uma mudança usando expressões mais cáusticas (e.g., "canhão” ou "jamanta” no linguajar popular carioca) serviria para recolocar o item no conjunto dos graves, algo perdido ao se aceitar simplesmente a tradução literal. Vale comentar que no presente estudo, a opção de somente adicionar “... ou outra coisa parecida", apesar de conservadora, intencionou manter a versão mais abrangente possível em relação ao contexto brasileiro. A proposição de termos paroquiais facilmente aceitos e entendíveis no Rio de Janeiro, poderia ser limitante, não sendo necessariamente pertinente, por exemplo, no contexto do Nordeste do país.

Este último comentário nos lembra que uma transposição cultural de um processo de aferição não se restringe a países e/ou idiomas distintos. Ajustes locais e regionais também requerem atenção (Badia et al., 1998; Dressler et al., 1997). O grau de sintonia com a população na qual a versão será usada é algo difícil de caracterizar. Uma decisão deve ponderar o quanto se ganha com a aproximação cultural e o quanto se pode perder em termos de generalização e comparabilidade.

A falta de uma correspondência conotativa pode ter reflexos importantes. Uma discrepância de poder emotivo que um termo tem em diferentes culturas pode acabar modificando a própria estrutura do instrumento. No caso do exemplo acima (gordo e feio), ao se manter a tradução literal sem qualquer adendo ou ajuste, a sub-escala de agressão psicológica grave acabaria com um item a menos, porquanto a de agressão psicológica menor, um a mais. Terse-ia, assim, alterada a validade de conteúdo do instrumento. Estas e outras sutilezas análogas merecem exploração mediante discussões que também incorporem membros da popula- ção onde, pretensamente, a versão seria utilizada. Neste sentido, estudos qualitativos através de estratégias de grupos focais seriam bastante profícuos. Aqui também são vitais os testes de campo e as avaliações psicométricas.

Merece lembrança que este problema não é reservado ao tema violência familiar. Herdman et al. (1998) alertam para as repercussões da falta de correspondência conotativa, usando como exemplo o conceito de "atividade de lazer" freqüentemente utilizado em instrumentos na área de avaliação de qualidade de vida. Apontam que o lazer significa coisas diferentes para grupos diferentes. Para uns, pode ser algo ativamente regojizado, para outros, apenas um simples relaxamento. Claramente, o que e quanto um determinado item abarcará dependerá do grupo ao qual o respondente se enquadra.

A discrepância observada entre os resultados da terceira e quarta etapas da apreciação da equivalência semântica, estimula o debate sobre o papel de cada procedimento na adaptação de instrumentos elaborados em outros contextos culturais (Guillemin et al. 1993; Perneger et al. 1999). Sem um aprofundamento após a terceira etapa do processo, a segunda retradução teria sido priorizada na construção da versão-síntese. Porém, uma vez detectado que os pequenos problemas com o par T1/R1 eram conseqüentes da retradução, e que a maioria dos itens da primeira tradução apresentava uma linguagem mais coloquial e adaptada ao contexto cultural brasileiro, optou-se, na maioria da vezes, pelos itens oriundos de T1. Esta ambigüidade poderia questionar a habitual importância dada à retradução nos processos de decisão. Talvez, valha recomendar que a apreciação formal da equivalência entre as retraduções e o original se restrinja a uma avaliação geral da qualidade das traduções, identificando as grandes discrepâncias entre as mesmas, e não, servir como critério principal para a escolha dos itens em si.

Essa sugestão, entretanto, merece qualificação. Segundo Guillemin et al. (1993), o ideal é que os retradutores tenham como língua-pátria aquela do instrumento original, e uma afinidade com a terminologia utilizada no campo temático em questão. A contragosto, os profissionais que participaram da etapa em questão não apresentavam este perfil. Vale comentar que essa não é uma situação rara em nosso meio. No Brasil, não existe ainda uma ampla oferta de tradutores especializados na área de Saúde Coletiva, muito menos na de violência familiar. De qualquer forma, do ponto de vista das decisões finais, é pouco plausível que o fato tenha trazido grande prejuízo, uma vez que 
na quarta etapa da avaliação pôde-se identificar os itens mal retraduzidos, passando-se para uma seleção diretamente guiada pela própria tradução. No presente estudo, o problema funcionou mais como um estorvo do que como uma fonte de viés.

O perfil dos tradutores também importa, como apontam vários autores ocupados com processos de adaptação de instrumentos (Alonso et al., 1990; Guillemin et al., 1993; Perneger et al., 1999). É possível que a melhor performance da primeira tradução esteja associada ao perfil do profissional que a elaborou. A tradução que deu origem a T1 foi realizada por um pesquisador da área de epidemiologia da violência familiar, o que levou a escolha de termos mais coloquiais e de uso corrente em pesquisas nessa área temática. Já a segunda versão foi elaborada por um profissional que, apesar de plenamente proficiente em inglês, não trabalhava no campo e, portanto, sem a mesma afinidade com a terminologia habitualmente empregada.

A existência de mais de um par de tradução-retradução facilitou a tomada de decisões para a elaboração da versão-síntese, algo também reportado em estudo anterior (Reichenheim et al., 2000). Porém, uma recomendação genérica sobre o número ideal de pares não parece interessante, na medida em que essa decisão está intimamente ligada ao custo-benefício do processo nos contextos específicos, isto é, a cada situação de pesquisa. Essa questão poderá ser oportunamente respondida com o incremento de programas de investigação que avaliem a efetividade das diferentes estratégias de adaptação transcultural.

Foi grande a influência da quarta etapa na elaboração da versão-síntese em português, tanto no ajuste final em termos de escolhas entre expressões semelhantes oriundas das duas traduções, quanto para lidar com problemas processuais. Por exemplo, o problema ventilado acima causado pelo fato dos profissionais envolvidos na etapa de retradução não terem o inglês como língua-pátria pôde ser contornado com essa avaliação mais detalhada. É a impressão dos autores que a etapa em muito contribuiu para a excelente aceitabilidade observada no campo e para que se alcançasse equivalência de significados satisfatória entre o instrumento original e sua versão. A importância de uma avaliação final interdisciplinar nos processos de adaptação não deve ser menosprezada.

A decisão de adaptar a versão-síntese para terceira pessoa se baseou na constatação de que, em função da baixa escolaridade de grande parte da população brasileira, as pesquisas na área de saúde costumam dar prioridade a entrevistas na coleta de informações. No entanto, não se deve perder a perspectiva de que processos de aferição baseados em auto-preenchimento, principalmente no campo da violência familiar, são em geral, mais acurados, pois são menos constrangedores e, quando desejado, podem garantir o anonimato (Pelton, 1979; Poteat et al., 1990). Nesse campo, a utilização de entrevistas tende a subestimar a ocorrência dos eventos. Por isso, o instrumento na forma de autopreenchimento também foi submetido às primeiras etapas do processo de adaptação e se encontra disponível com os autores. Ressalta-se, porém, que não tendo sido ainda submetido a um pré-teste, sua utilização imediata ainda não pode ser recomendada sem restrição.

As raras dificuldades encontradas na aplicação da escala de coerção sexual não parecem ser exclusividade da CTS2. Segundo pesquisas realizadas com vítimas de abuso sexual, uma das principais questões envolvidas concerne o "esquecimento" e a negação proposital do evento pelos indivíduos, como uma forma de adaptação à experiência de violência vivenciada. Freqüentemente, são necessárias estratégias de identificação especializadas, envolvendo entrevistas regulares com profissionais de formação na área temática (Bradley \& Wood, 1996; Leavitt, 2000; Sorenson \& Snow, 1991). Ainda assim, a despeito das dificuldades, não seria prudente interromper o processo de aprimoramento de instrumentos estruturados e mais simples como a CTS2, já que estes continuam sendo a principal ferramenta diagnóstica para uso em estudos clínicos e epidemiológicos.

A partir da avaliação da equivalência conceitual, de itens e semântica pôde-se propor uma primeira versão em português da CTS2. No entanto, ainda restam alguns passos para se aceitar com certa segurança que a equivalência transcultural entre o original e a versão tenha sido plenamente alcançada. Conforme já exposto na introdução, a apreciação da equivalência de mensuração, estudada através da comparação entre as propriedades psicométricas da versão em português e do instrumento original, é mais uma tarefa importante nesse processo e será realizada no futuro próximo. Além disso, é fundamental que esta primeira versão seja posta à crítica pelos profissionais interessados. A vasta gama de detalhes e opções, muitas delas intrinsecamente subjetivas, demanda que o aprimoramento do instrumento adaptado dependa de um debate e negociações contínuas entre pares.

Em uma perspectiva mais geral, valeria retomar e discutir algumas facetas próprias dos procedimentos de adaptação transcultural de ins- 
trumentos. Boa parte das questões discutidas acima já vem sendo percebida e alvo de debate em estudos de outras áreas temáticas, como por exemplo, a de qualidade de vida e saúde.

Vários autores têm exaltado a qualidade dos instrumentos de aferição e os processos de coleta de informações, como componentes de sustentação da validade de informação em estudos epidemiológicos (Kraemer, 1992; Moser \& Kalton, 1984; Reichenheim \& Moraes, 1998; Shrout, 1998; Streiner \& Norman, 1995). A experiência relatada aqui sobre o processo de adaptação transcultural da CTS2, não só refor- ça este clamor mas o direciona para um contexto como o nosso, em que é comum o uso de instrumentos de aferição construídos em outras culturas. Aqui, informações robustas, e logo, inferências válidas, requerem ainda mais detalhes e rigores. As pequenas e grandes decisões apresentadas em cada uma das etapas da adaptação tentaram ressaltar a importância dessa sintonia fina, principalmente quando há pretensão de comparações interculturais válidas de objetos tão complexos e escorregadiços, como é o caso da violência familiar.

\section{Agradecimentos}

Os autores agradecem às demais participantes do grupo de especialistas, Simone de Assis e Barbara Musumeci Soares pela disponibilidade em participar do estudo e pela riqueza de suas contribuições. Também agradecem à Christopher Peterson por sua engajada participação na 3a etapa de avaliação da equivalência semântica, e às entrevistadoras Alessandra Veggi, Fernanda Faria de Almeida, Isabella Mota Rezende, Joelma Castro e Juliana Toshica Kunisawa, pelos valiosos comentários oferecidos durante a fase de pré-teste do instrumento. Projeto apoiado pelo Programa de Apoio aos Núcleos de Excelência (PRONEX) / Conselho Nacional de Desenvolvimento Científico e Tecnológico (CNPq), processo 663073/9987 e Fundação Carlos Chagas Filho de Amparo à Pesquisa do Estado do Rio de Janeiro, processos E-26/171.223/98 e E-26/150.893/99. Apoiado pelo CNPq, processo 300234/94-5. C.L. apoiada por Bolsa de Estudos da Escola Nacional de Saúde Pública, Fundação Oswaldo Cruz.

\section{Referências}

ABRAPIA (Associação Brasileira de Proteção à Infância e Adolescência), 1992. Maus Tratos Contra Crianças e Adolescentes. Proteção e Prevenção. Guia de Orientação para Profissionais de Saúde. Rio de Janeiro: ABRAPIA.

ALONSO, J.; ANTO, J. M. \& MORENO, C., 1990. Spanish version of the Nottingham health profile: Translation and preliminary validity. American Journal of Public Health, 80:704-708.

BADIA, X. \& ALONSO, J., 1995. Re-scaling the Spanish version of the sickness impact profile: An opportunity for the assessment of cross-cultural equivalence. Journal of Clinical Epidemiology, 48:949-957.

BADIA, X.; SCHIAFFINO, A.; ALONSO, J. \& HERDMAN, M., 1998. Using the EuroQol 5-D in the Catalan general population: Feasibility and construct validity. Quality of Life Research, 7:311-322.

BEMFAM (Sociedade Civil de Bem-Estar Familiar no Brasil), 1998. Cidadão Adolescente. Rio de Janeiro: BEMFAM.

BRADLEY, A. R. \& WOOD, J. M., 1996. How do children tell? The disclosure process in child sexual abuse. Child Abuse \& Neglect, 20:881-891.

BRANCO, V. M. C.; PHEBO, L.; GOMES, M. A. S. M.; CASTRO, A. M. M. \& NOGUEIRA, M. A., 1996. Protegendo Nossas Crianças e Adolescentes. Rio de Janeiro: Secretaria Municipal de Saúde do Rio de Janeiro. 
BRAVO, M.; CANINO, G. J.; RUBIO-STIPEC, M. \& WOODBURY-FARINA, M., 1991. A cross-cultural adaptation of a psychiatric epidemiologic instrument: The diagnostic interview schedule's adaptation in Puerto Rico. Culture, Medicine and Psychiatry, 15:1-18.

BUCQUET, S.; CONDON, S. \& RITCHIE, K., 1990. The French version of the Nottingham Health Profile: A comparison of items weights with those of the source version. Social Science and Medicine, 30: 829-835.

DESLANDES, S. F., 1994. Prevenir a Violência: Um Desafio para Profissionais de Saúde. v. 2. Rio de Janeiro: Centro Latino-Americano de Estudos de Violência e Saúde Jorge Careli, Escola Nacional de Saúde Pública, Fundação Oswaldo Cruz.

DRESSLER, W. W.; BALIEIRO, M. C. \& SANTOS, J. E., 1997. The cultural construction of social support in Brazil: Associations with health outcomes. Culture, Medicine and Psychiatry, 21:303-335.

GELLES, R. J., 1997. Intimate Violence in Families. London: Sage Publications.

GUERRA, V., 1998. Violência de Pais Contra Filhos: A Tragédia Revisitada. São Paulo: Cortez Editora.

GUILLEMIN, F.; BOMBARDIER, C. \& BEATON, D., 1993. Cross-cultural adaptation of health-related quality of life measures: Literature review and proposed guidelines. Journal of Clinical Epidemiology, 46:1417-1432.

HEISE, L., 1994. Gender-based abuse: The global epidemic. Cadernos de Saúde Pública, 10:135-145.

HEISE, L. L.; PITANGUY, J. \& GERMAIN, A., 1994. Violence Against Women: The Hidden Health Burden. Washington, DC: World Bank.

HERDMAN, M.; FOX-RUSHBY, J. \& BADIA, X., 1997. "Equivalence" and the translation and adaptation of health-related quality of life questionnaires. Quality of Life Research, 6:237-247.

HERDMAN, M.; FOX-RUSHBY, J. \& BADIA, X., 1998. A model of equivalence in the cultural adaptation of HRQoL instruments: The universalist approach. Quality of Life Research, 7:323-335.

INCLEN (International Clinical Epidemiology Network), 2000. Worldsafe and indiasafe: Studying the prevalence of family violence. INCLEN Monograph Series on Critical International Health Issues, 9:1-15.

KRAEMER, H. C., 1992. Measurement of reliability for categorical data in medical research. Statistical Methods in Medical Research, 1:183-199.

LEAVITT, F., 2000. Surviving roots of trauma: Prevalence of silent signs of sex abuse in patients who recover memories of childhood sex abuse as adults. Journal of Personality Assessment, 74:311-323.

MORAES, C. L., 1998. Estudo Caso-Controle da Violência Familiar como um Fator de Propensão à Prematuridade do Recém-nascido. Rio de Janeiro: Instituto de Medicina Social, Universidade do Estado do Rio de Janeiro. (mimeo.)

MOSER, C. A. \& KALTON, G., 1984. Survey Methods in Social Investigation. 2nd Ed. London: Heinemann.

MS (Ministério da Saúde), 1997. Violência Contra a Criança e o Adolescente: Proposta Preliminar de Prevenção e Assistência à Violência Doméstica. Brasília: MS.
PATRICK, D. L.; SITTAMPALAM, Y.; SOMERVILLE, S. M.; CARTER, W. B. \& BERGNER, M., 1985. A crosscultural comparison of health status values. American Journal of Public Health, 75:1402-1407.

PELTON, L. G., 1979. Interpreting family violence data. American Journal of Orthopsychiatry, 49:194.

PERNEGER, T. V.; LEPLÈGE, A. \& ETTER, J.-F., 1999. Cross-cultural adaptation of a psychometric instrument: Two methods compared. Journal of Clinical Epidemiology, 52:1037-1046.

POTEAT, G. M.; GROSSNICKLE, W. F.; COPE, J. G. \& WYNNE, D. C., 1990. Psychometric properties of the Wife Abuse Inventory. Journal of Clinical Psychology, 46:828-834.

REICHENHEIM, M. E. \& MORAES, C. L., 1998. Alguns pilares para a apreciação da validade de estudos epidemiológicos. Revista Brasileira de Epidemiologia, 1:131-148.

REICHENHEIM, M. E.; MORAES, C. L. \& HASSELMANN, M. H., 2000. Equivalência semântica da versão em português do instrumento Abuse Assessment Screen para rastrear a violência contra a mulher grávida. Revista de Saúde Pública, 34:610-616.

SHROUT, P. E., 1998. Measurement reliability and agreement in psychiatry. Statistical Methods in Medical Research, 7:301-317.

SOARES, B. M.; GASPARY, M. C. \& INGELFRITZ, I., 1999. Textos Selecionados: Violência Intrafamiliar Contra a Mulher. Rio de Janeiro: Subsecretaria de Pesquisa e Cidadania, Secretaria de Estado de Segurança Pública.

SORENSON, T. \& SNOW, B., 1991. How children tell: The process of disclosure in child sexual abuse. Child Welfare, 70:3-15.

STRAUS, M. A., 1979. Measuring intra-familiar conflict and violence: The conflict tactics (CT) scales. Journal of Marriage and Family, 41:75-88.

STRAUS, M., 2000. Handbook for the Conflict Tactics Scales (CTS). Durham: Family Research Laboratory, University of New Hampshire.

STRAUS, M. A. \& GELLES, R. J., 1995. Physical Violence in American Families: Risk Factors and Adaptations to Violence in 8145 Families. New Brunswick: Transaction Publisher.

STRAUS, M. A.; HAMBY, S. L.; BONEY-McCOY, S. \& SUGARMAN, D. B., 1996. The revised Conflict Tactics Scales (CTS2): Development and preliminary psychometric data. Journal of Family Issues, 17:283-316.

STRAUS, M. A.; HAMBY, S. H.; FINKELHOR, D.; MOORE, D. W. \& RUNYAN, D., 1998. Identification of child maltreatment with parent-child conflict tactics scales: Development and psychometric data for a national sample of American parents. Child Abuse \& Neglect, 22:249-270.

STREINER, D. L. \& NORMAN, G. R., 1995. Health Measurement Scales. A Practical Guide to Their Development and Use. 2nd Ed. Oxford: Oxford University Press.

Recebido em 29 de janeiro de 2001

Versão final reapresentada em 17 de maio de 2001

Aprovado em 15 de agosto de 2001 